\title{
Frequency and Antimicrobials Susceptibility Pattern of Staphylococcus aureus Associated with Wound Infections in Surgery Department, Wad Madani Teaching Hospital, Sudan
}

\author{
Sanaa M. Yousif', Adam D. Abakar², Bakri Y. M. Nour², Salma 0. Ibrahim³, Omer M. Abu Elhasan", \\ Mirgani A. Yousif ${ }^{5}$, Sitelbanat Yassin ${ }^{5}$, Hajer M. Hussien33, Mohamed Taj-Eldin ${ }^{3}$, Elhadi A. Ahmed ${ }^{3}$ \\ ${ }^{1}$ National Blood Bank, Ministry of Health, Khartoum, Sudan \\ ${ }^{2}$ Department of Medical Parasitology, Faculty of Medical Laboratory Sciences, University of Gezira, Wad Medani, Sudan \\ ${ }^{3}$ Department of Medical Microbiology, Faculty of Medical Laboratory Sciences, University of Gezira, Wad Medani, Sudan \\ ${ }^{4}$ Wad-Madani College of Medical Sciences and Technology, Wad Medani, Sudan \\ ${ }^{5}$ Faculty of Pharmacy, University of Gezira, Wad Medani, Sudan \\ Email: ^hadilabone@yahoo.com, ^hadilabone@uofg.edu.sd
}

How to cite this paper: Yousif, S.M., Abakar, A.D., Nour, B.Y.M., Ibrahim, S.O., Elhasan, O.M.A., Yousif, M.A., Yassin, S., Hussien, H.M., Taj-Eldin, M. and Ahmed, E.A. (2021) Frequency and Antimicrobials Susceptibility Pattern of Staphylococcus aureus Associated with Wound Infections in Surgery Department, Wad Madani Teaching Hospital, Sudan. Pharmacology \& Pharmacy, 12, 334-343.

https://doi.org/10.4236/pp.2021.1212028

Received: November 3, 2021

Accepted: December 27, 2021

Published: December 30, 2021

Copyright $\odot 2021$ by author(s) and Scientific Research Publishing Inc. This work is licensed under the Creative Commons Attribution International License (CC BY 4.0).

http://creativecommons.org/licenses/by/4.0/

\begin{abstract}
Background: Most community and hospital acquired infections are due to Staphylococcus aureus, these infections involve both local suppurative and systemic conditions. There is an increase in the incidence rates of acquiring resistant strains of Staphylococcus aureus in hospitals and community in Sudan. This study aims to detect frequency of Staphylococcus aureus isolated from surgical-sites infections (SSIs) and traumatic wounds, and to determine susceptibility to commonly used drugs. Methods: Prospective cross-sectional laboratory based study was followed, 250 patients admitted to Surgery Departments at Wad Madani Teaching Hospitals during 2019 and 2020 were recruited; with clinical manifestation of SSIs and or/traumatic wounds. Swab sample was taken from each participant and incubated aerobically on mannitol salt agar. Biochemical tests and 16rRNA gene used for Staphylococcus aureus identification. Antimicrobial susceptibility was accomplished using Kirby Bauer disc diffusion technique. Results: Infection rate of wounds in males and females equal $71 \%(17 / 250)$ and $29 \%(73 / 250)$, while infection rate in the age group of 41 to 60 years was the highest with percentage of $49 \%(122 / 250)$. Staphylococcus aureus constituting 76\% (181/238) as predominant isolates. SSIs isolates of Staphylococcus aureus were highly resistant to tested antimicrobials. Meropeneme was the drug of choice with sensitivity of $88 \%$ and $100 \%$ for SSIs and traumatic wounds isolates respectively. Conclusion: In hospitals and community Staphylococcus aureus remain the most common
\end{abstract}


cause of wounds infections. The high resistance to used drugs shown by Staphylococcus aureus in this study requires an assessment of the current situation and finding of more effective anti-staphylococcals.

\section{Keywords}

Staphylococcus aureus, Surgical-Sites, Wounds, Meropeneme, Sudan

\section{Introduction}

Staphylococcus aureus is responsible for wide range of community and hospital acquired infections; these infections involve both local suppurative conditions such as skin and skin structures infections and systemic life-threatening sepsis [1] [2] [3].

According to Silverberg [4] and Taylor and Unkal [5], skin invasion by microorganism result from weakening of the skin's defenses against microbial invasion. Notice that, skin is most commonly breach by traumas and intentional medical procures. Traumatic wounds in community usually acquire bacteria either from normal microbiota of humans or from exogenous sources, however, it is still possible to gain bacteria from hospital sources during prolonged staying. In hospital settings Staphylococcus aureus could be transmitted from one patient to other through contact with contaminated objects, from air, during wounds dressing and invasive procedures. Additionally, SSIs have serious consequences for surgeons, patients, and institutions that double the risk of patient death [6] [7] [8].

Staphylococcus that associated with SSI infection is frequently reported to develop multidrug-resistant against a wide spectrum of commonly used antibiotics [9] [10]. The increase in incidence rates of MRSA and its spread in hospitals and the community as studied by Mohammed et al., [11] and Abdalhay et al., [12] it is highly prevalent among populations of Staphylococcus aureus isolated from different clinical specimens in different hospitals in Sudan, had posed a major challenge for infections treatment.

Understanding the prevalence of Staphylococcus aureus, antibiotic resistance patterns, and accurate and reliable detection methods are necessary for proper antibiotic treatment and effective control measures. In Sudan, scattered data concerning multi-drug resistant (MDR) Staphylococcus aureus is available, the only documented research for development of MDR was reported by Onyeka et al., [13], Hassan et al., [14] and Azab et al., [15]. Therefore, the current study aimed to evaluate the Staphylococcus aureus as a cause of wound infections and the effectiveness of used drugs.

\section{Methods}

\subsection{Study Area and Design}

This was prospective cross-sectional laboratory based study conducted from 
2019 to 2020 at Wad Madani Teaching Hospital, Sudan. As Wad Madani city is the capital of Gezira State, department of general surgery consider as a referral center for management of surgical and wound infections around the state.

\subsection{Case Definition and Sample Size}

The study included patients admitted to department of general surgery with clinical manifestations of SSIs and or/traumatic wounds; cases of SSIs were those acquired infection at the site of surgery during hospitalization while traumatic wounds cases were admitted to the department with infection symptoms. Two hundred and fifty patients were recruited after satisfaction of selection criteria.

\subsection{Collection of Samples}

Swab samples were obtained from infected areas avoiding external skin touching using sterile cotton device. To insure collection of sufficient amount of bacteria swabs were introduce deeply with rotation for few seconds. Swabs were labeled with the corresponding subject number and sent to microbiology laboratory of the Faculty of Medical Laboratory Sciences for immediate processing.

\subsection{Isolation and Identification}

All swabs were inoculated on mannitol salt agar medium and incubated for 24 hrs at $37^{\circ} \mathrm{C}$. The colonies then identified by mannitol fermentation, Gram's staining, catalase, slide coagulase, tube coagulase tests and 16rRNA gene amplification using universal bacterial primers; 27F:

5'AGAGTTTGATCCTGGCTCAG-3' and 1492R:

5'-GGTTACCTTGTTACGACTT-3' (16).

\subsection{Antimicrobial Susceptibility Testing}

The isolates of Staphylococcus aureus were tested against vancomycin (30 $\mu \mathrm{g})$, meropeneme $(10 \mu \mathrm{g})$, gentamicin $(30 \mu \mathrm{g})$, ciprofloxacin $(5 \mu \mathrm{g})$, amoxicillin-clavuanic acid (Augmentin) $(30 \mu \mathrm{g})$, cefuraxime $(30 \mu \mathrm{g})$, ceftriaxone (30 $\mu \mathrm{g})$, cefatoxime $(30 \mu \mathrm{g})$ and cefepeme $(30 \mu \mathrm{g})$, and Agar disc diffusion was followed according to CLSI guidance. In procedure, overnight growth of Staphylococcus aureus cultures were adjusted to turbidity of $0.5 \mathrm{McFarland}$ standards. The bacterial suspensions were spread on Mueller-Hinton agar. All plates were incubated at $37^{\circ} \mathrm{C}$ for 24 hours before reading the results. According to zones of inhibition isolates reported as sensitive, intermediate resistant and resistant.

\subsection{Statistics}

A simple descriptive analysis was followed to find out the frequency of Staphylococcus aureus patient's demographics and the efficacy of tested drugs.

\section{Results}

Male participants, age group from 41 to 60 years, rural residence and diabetes 
mellitus were reported in 71\% (177/250), 49\% (122/250), 69\% (173/250) and $8.4 \%(21 / 250)$ of enrolled patients respectively (Table 1 ). Positive bacterial growth was showed in 95\% (238/250). Staphylococcus aureus isolates predominated with percentage of $76 \%(181 / 238)$ followed by gram negative bacteria $15 \%(35 / 238)$ and coagulase negative staphylococcus $4 \%$ (9/238), polymicrobial growth revealed in 5\% (13/238) (Figure 1). With SSIs, 68\% (115/170) of samples gave positive growth for Staphylococcus aureus and 81\% (65/80) from traumatic wounds (Table 2). The antibiotics susceptibility of isolated Staphylococcus aureus against different antimicrobial candidates for SSIs and traumatic wounds were depicted in (Table 3) and (Table 4). All tested isolates of Staphylococcus aureus were fully susceptible to vancomycin. The effective drug against SSIs isolates with sensitivity of $88 \%$ was meropeneme followed by gentamycin $(38 \%)$. While isolates from traumatic wounds expressed full susceptibility to meropeneme and $71 \%$ to gentamicin. The high resistance of both SSIs and traumatic wounds isolates was recorded against cefepeme followed by cefatoxime and ceftriaxone.

Table 1. Demographic characteristics of study subject.

\begin{tabular}{|c|c|c|}
\hline Characteristics & Frequency & Percentage \\
\hline \multicolumn{3}{|l|}{ Sex } \\
\hline Male & 177 & 71 \\
\hline Female & 73 & 29 \\
\hline Total & 250 & 100 \\
\hline \multicolumn{3}{|l|}{ Age group } \\
\hline $18-40$ & 72 & 29 \\
\hline $41-60$ & 122 & 49 \\
\hline$>60$ & 56 & 22 \\
\hline Total & 250 & 100 \\
\hline Residence & 77 & 31 \\
\hline Urban & 173 & 69 \\
\hline Rural & 250 & 100 \\
\hline Total & & \\
\hline \multicolumn{3}{|l|}{ Type of wound } \\
\hline Surgical-site & 170 & 68 \\
\hline Traumatic & 80 & 32 \\
\hline Total & 250 & 100 \\
\hline \multicolumn{3}{|l|}{ Diabetes mellitus } \\
\hline Yes & 21 & 8.4 \\
\hline No & 229 & 91.6 \\
\hline Total & 250 & 100 \\
\hline \multicolumn{3}{|l|}{ Wounds location } \\
\hline Abdomen & 128 & 51 \\
\hline Foot & 64 & 26 \\
\hline Hand & 53 & 21 \\
\hline Back & 5 & 2 \\
\hline Total & 250 & 100 \\
\hline
\end{tabular}




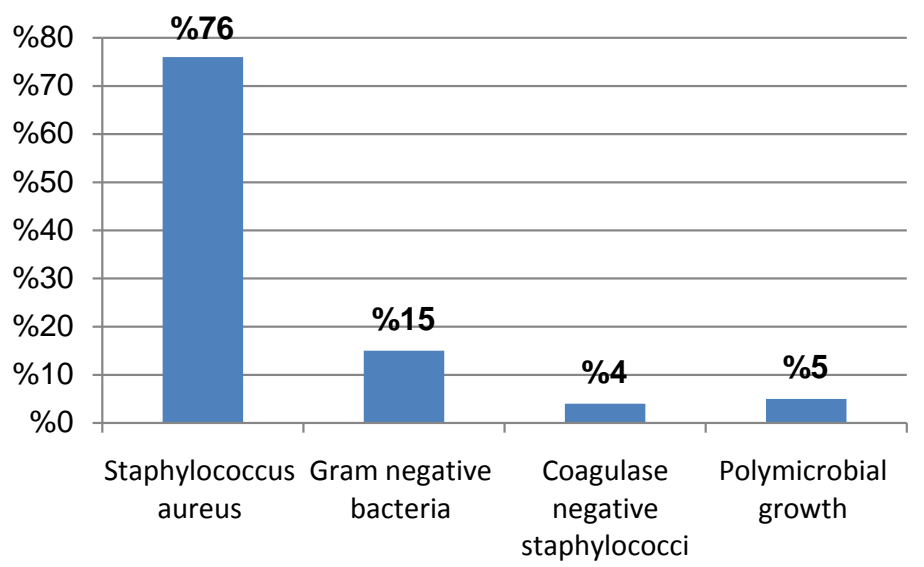

Isolates

Figure 1. Distriubuation of bacterial growth associated with wound infections in study subjects.

Table 2. Frequency of Staphylococcus aureus isolated from SSIs and traumatic wounds.

\begin{tabular}{ccccc}
\hline & $\begin{array}{c}\text { Staphylococcus } \\
\text { aureus }(\%)\end{array}$ & $\begin{array}{c}\text { Other growth } \\
(\%)\end{array}$ & $\begin{array}{c}\text { No growth } \\
(\%)\end{array}$ & $\begin{array}{c}\text { Total } \\
(\%)\end{array}$ \\
\hline \multirow{2}{*}{ SSIs } & 115 & 49 & 6 & 170 \\
& $(68)$ & $(29)$ & $(3)$ & $(100)$ \\
\hline \multirow{2}{*}{ Traumatic wounds } & 65 & 8 & 7 & 80 \\
& $(81)$ & $(10)$ & $(9)$ & $(100)$
\end{tabular}

Table 3. Antimicrobial susceptibilty pattern of Staphylococcus aureus isolated from SSIs.

\begin{tabular}{ccccccc}
\hline \multirow{2}{*}{ Antibiotic } & \multicolumn{2}{c}{ Sensitive } & \multicolumn{2}{c}{ Intermediate/resistant } & \multicolumn{2}{c}{ Resistant } \\
\cline { 2 - 7 } & No & $\%$ & No & $\%$ & No & $\%$ \\
\hline Vancomycin & 116 & 100 & 0 & 0 & 0 & 0 \\
Meropeneme & 102 & 88 & 4 & 3 & 10 & 8 \\
Gentamicin & 44 & 38 & 27 & 23 & 45 & 39 \\
Ciprofloxacin & 34 & 29 & 25 & 21 & 57 & 50 \\
Augmentin & 22 & 19 & 22 & 19 & 72 & 62 \\
Cefuraxime & 21 & 18 & 14 & 12 & 81 & 70 \\
Ceftriaxone & 23 & 20 & 8 & 7 & 85 & 73 \\
Cefatoxime & 21 & 18 & 7 & 6 & 88 & 76 \\
Cefepeme & 2 & 2 & 11 & 9 & 103 & 89 \\
\hline
\end{tabular}

Table 4. Antimicrobial susceptibilty pattern of Staphylococcus aureus isolated from traumatic wounds.

\begin{tabular}{ccccccc}
\hline \multirow{2}{*}{ Antibiotic } & \multicolumn{2}{c}{ Sensitive } & \multicolumn{2}{c}{ Intermediate/resistant } & \multicolumn{2}{c}{ Resistant } \\
\cline { 2 - 7 } & No & $\%$ & No & $\%$ & No & $\%$ \\
\hline Vancomycin & 65 & 100 & 0 & 0 & 0 & 0 \\
Meropeneme & 65 & 100 & 0 & 0 & 0 & 0 \\
\hline
\end{tabular}




\begin{tabular}{ccccccc} 
Continued & \multicolumn{1}{c}{} & & & & \\
\hline Gentamicin & 46 & 71 & 13 & 20 & 6 & 9 \\
Ciprofloxacin & 32 & 49 & 14 & 22 & 19 & 29 \\
Augmentin & 13 & 20 & 24 & 37 & 28 & 43 \\
Cefuraxime & 20 & 31 & 9 & 14 & 36 & 55 \\
Ceftriaxone & 22 & 34 & 7 & 11 & 36 & 55 \\
Cefatoxime & 19 & 29 & 5 & 8 & 41 & 63 \\
Cefepeme & 5 & 8 & 9 & 14 & 51 & 78
\end{tabular}

\section{Discussion}

Without a doubt, Staphylococcus aureus is the most important species agent of wound infections at the hospital and community level, this can be explained by the fact that it is wide-spread in nature and the environment, in addition to being a normal microbiota in noses and skin of a significant proportion of people [17] [18]. From the current study, Staphylococcus aureus was identified in 76\% of wounds samples; this high rate of the spread of Staphylococcus aureus as a causative agent of wound infections in hospitals and the community is attributable to what was previously mentioned, in addition to the poor level of personal hygiene and susceptibility to infection in elderly people and those with immunocompromised diseases such as diabetes, and this within the community [19]. Many documents refer to the predominance of Staphylococcus aureus as unique agent of wounds infection [20] [21].

At hospital setting other factors have a role in the prevalence; at the level of causative agent the virulence, ability to resist antimicrobial and disinfectants, and biofilm formation are major factors distinguish hospital Staphylococcus aureus [3]. Absence of infection control program in hospitals in Sudan and most developing countries has a great effect on the effectiveness of transmission of bacteria between patients and hospital environment. Also there is no solid systematic guidelines for wound infections medication involves proper care and application of drug sensitivity testing for infected patients.

Males in the current study accounted for $71 \%$ of total cases, from our knowledge, male gender was considered to be a risk factor for infection following trauma [22] and for SSIs [23] [24]. In line, Zhang and his group emphasized that differences in infection rate between male and female can occur due to anatomical sites, health behaviors, environmental experiences, stress and exposure to risk [25]. From the results, cases came that from rural residence were higher than urban; this may be attributed to the hard works in rural such as agriculture, lack of care for personal hygiene, and the absence of surgical unites in rural hospitals [26].

Investigating the prevalence rates of antimicrobial resistance among wound infections pathogens is critical for establishing treatment strategies and evaluating current guidelines [15] [27] [28]. Our result showed marked variability in 
antimicrobial sensitivity of Staphylococcus aureus strains that isolated from SSIs and traumatic wounds, with the exception of vancomycin which revealed susceptibility of $100 \%$ at all as a drug of choice [29]. With less degree meropeneme gave sensitivity of $88 \%$ in SSIs and $100 \%$ in traumatic wounds isolates, luckily, two genes encoding for carbapenems resistance were identified (data not shown).

The high sensitivity to gentamycin among traumatic wounds Staphylococcus aureus isolates is due to the restriction use of this injection in the hospitals and it is limitations, and thus only $9 \%$ of traumatic wounds isolated strains appeared as resistant. Resistance to gentamycin of relatively higher percentage was recorded in hospitals in north Ethiopia [30].

Importantly, the study findings expressed high resistance to third and fourthgeneration cephalosporines; ceftriaxone and cefepeme. Cephalosporines prophylaxis is commonly used in surgery practices in most hospitals in Sudan. In addition to the usage for treatment of sepsis, acute pneumonia and post-operative situations. So, continuous exposure of bacteria such as Staphylococcus aureus to cephalosporines and hospital over-prescription may be enrolled as prediction for failure of treatment [31] [32] [33].

In conclusion, the study highlights the antimicrobials prescribed mainly for wound infections, as well as the dominance of Staphylococcus aureus as etiologic agents. In Sudan cephalosporines remain the main option in antibiotic therapy of wounds, and the most commonly prescribed one; ceftriaxone resulted in low susceptibility.

\section{Study Limitation}

This study did not determined the percentage of methicillin-resistant Staphylococcus aureus due to the sufficient previous studies, and it also did not classified the infections of surgical-sites based on the type of operation. However, this work is comprehensive analysis of the use of the most important antibiotics for the treatment of infected wounds and corresponding antimicrobial resistance.

\section{Conflicts of Interest}

The authors declare no conflicts of interest regarding the publication of this paper.

\section{References}

[1] Guo, Y., Song, G., Sun, M., Wang, J. and Wang, Y. (2020) Prevalence and Therapies of Antibiotic-Resistance in Staphylococcus aureus. Frontiers in Cellular and Infection Microbiology, 10, Article No. 107. https://doi.org/10.3389/fcimb.2020.00107 https://www.frontiersin.org/articles/10.3389/fcimb.2020.00107/full

[2] Cruz, A.R., van Strijp, J.A.G., Bagnoli, F. and Manetti, A.G.O. (2021) Virulence Gene Expression of Staphylococcus aureus in Human Skin. Frontiers in Microbiology, 12, Article ID: 692023. https://doi.org/10.3389/fmicb.2021.692023

[3] Idrees, M., Sawant, S., Karodia, N. and Rahman, A. (2021) Staphylococcus aureus Biofilm: Morphology, Genetics, Pathogenesis and Treatment Strategies. International 
Journal of Environmental Research and Public Health, 18, Article No. 7602. https://doi.org/10.3390/ijerph18147602

[4] Silverberg, B. (2021) A Structured Approach to Skin and Soft Tissue Infections (SSTIs) in an Ambulatory Setting. Clinics and Practice, 11, 65-74. https://doi.org/10.3390/clinpract11010011

[5] Taylor, T.A. and Unakal, C.G. (2021) Staphylococcus aureus. StatPearls Publishing, Treasure Island, FL. http://www.ncbi.nlm.nih.gov/books/NBK441868/

[6] Darboe, S., Dobreniecki, S., Jarju, S., Jallow, M., Mohammed, N.I., Wathuo, M., et al. (2019) Prevalence of Panton-Valentine Leukocidin (PVL) and Antimicrobial Resistance in Community-Acquired Clinical Staphylococcus aureus in an Urban Gambian Hospital: A 11-Year Period Retrospective Pilot Study. Frontiers in Cellular and Infection Microbiology, 9, Article No. 170.

https://doi.org/10.3389/fcimb.2019.00170

[7] Pal, S., Sayana, A., Joshi, A. and Juyal, D. (2019) Staphylococcus aureus: A Predominant Cause of Surgical Site Infections in a Rural Healthcare Setup of Uttarakhand. Journal of Family Medicine and Primary Care, 8, 3600-3606.

[8] Giudice, P. (2020) Skin Infections Caused by Staphylococcus aureus. Acta Dermato- Venereologica, 100, adv00110.

[9] Ma, Y., Zhao, Y., Tang, J., Tang, C., Chen, J. and Liu, J. (2018) Antimicrobial Susceptibility and Presence of Resistance \& Enterotoxins/Enterotoxin-Likes Genes in Staphylococcus aureus from Food. CyTA-Journal of Food, 16, 76-84. https://doi.org/10.1080/19476337.2017.1340341

[10] Wolters, M., Frickmann, H., Christner, M., Both, A., Rohde, H., Oppong, K., et al. (2020) Molecular Characterization of Staphylococcus aureus Isolated from Chronic Infected Wounds in Rural Ghana. Microorganisms, 8, Article No. 2052.

https://doi.org/10.3390/microorganisms8122052

[11] Mohammed, A.E.D., Mohamed, M., Goda, A. and Mohamed, S. (2018) Antimicrobial Resistance Pattern of Staphylococcus aureus Isolated from Infected Wounds at Sohag University Hospitals. Sohag Medical Journal, 22, 179-187. https://doi.org/10.21608/smj.2018.32146

[12] Abdalhay, A.O., Ahmed, S. and Musa, M. (2020) Epidemiology and Risk Factors of Methicillin-Resistant Staphylococcus aureus Complicated Otorhinolaryngological Cases at Khartoum ENT Hospitals in Khartoum State, Sudan in 2017. Pan Arab Journal of Rhinology, 10, 54-57. https://doi.org/10.4103/pajr.pajr_14_19

[13] Onyeka, F., Nwobodo, D., Umenne, I., Atada, E., Ojukwu, C., Aniekwe, M., et al. (2020) Antibiotic Resistance Pattern of Staphylococcus aureus Isolated from Nostrils of Healthy Undergraduates of Madonna University Elele Campus, Rivers State, Nigeria. Microbes and Infectious Diseases, 2, 280-285.

https://doi.org/10.21608/mid.2020.33006.1023

[14] Hassan, R.S.E.E., Osman, S.O.S., Aabdeen, M.A.S., Mohamed, W.E.A., Hassan, R.S.E.E. and Mohamed, S.O.O. (2020) Incidence and Root Causes of Surgical Site Infections after Gastrointestinal Surgery at a Public Teaching Hospital in Sudan. Patient Safety in Surgery, 14, Article No. 45. https://doi.org/10.1186/s13037-020-00272-4

[15] Azab, K.S.M., Abdel-Rahman, M.A., El-Sheikh, H.H., Azab, E., Gobouri, A.A. and Farag, M.M.S. (2021) Distribution of Extended-Spectrum $\beta$-Lactamase (ESBL)-Encoding Genes among Multidrug-Resistant Gram-Negative Pathogens Collected from Three Different Countries. Antibiotics, 10, Article No. 247.

https://doi.org/10.3390/antibiotics10030247 
[16] Dos Santos, H.R.M., Argolo, C.S., Argôlo-Filho, R.C., et al. (2019) A 16S rDNA PCR-Based Theoretical to Actual Delta Approach on Culturable Mock Communities Revealed Severe Losses of Diversity Information. BMC Microbiology, 19, Article No. 74. https://doi.org/10.1186/s12866-019-1446-2

[17] Dessie, W., Mulugeta, G., Fentaw, S., Mihret, A., Hassen, M. and Abebe, E. (2016) Pattern of Bacterial Pathogens and Their Susceptibility Isolated from Surgical Site Infections at Selected Referral Hospitals, Addis Ababa, Ethiopia. International Journal of Microbiology, 2016, Article ID: 2418902. https://doi.org/10.1155/2016/2418902

[18] Chaudhary, R., Thapa, S.K., Rana, J.C. and Shah, P.K. (2017) Surgical Site Infections and Antimicrobial Resistance Pattern. Journal of Nepal Health Research Council, 15, 120-123. https://doi.org/10.3126/jnhrc.v15i2.18185

[19] Raeder, K., Jachan, D.E., Müller-Werdan, U. and Lahmann, N.A. (2020) Prevalence and Risk Factors of Chronic Wounds in Nursing Homes in Germany. International Wound Journal, 17, 1128-1134. https://doi.org/10.1111/iwj.13486

[20] Bessa, L.J., Fazii, P., Giulio, M.D. and Cellini, L. (2015) Bacterial Isolates from Infected Wounds and Their Antibiotic Susceptibility Pattern: Some Remarks about Wound Infection. International Wound Journal, 12, 47-52.

https://doi.org/10.1111/iwj.12049

[21] Upreti, N., Rayamajhee, B., Sherchan, S.P., Choudhari, M.K. and Banjara, M.R. (2018) Prevalence of Methicillin Resistant Staphylococcus aureus, Multidrug Resistant and Extended Spectrum $\beta$-Lactamase Producing Gram Negative Bacilli Causing Wound Infections at a Tertiary Care Hospital of Nepal. Antimicrobial Resistance \& Infection Control, 7, Article No. 121. https://doi.org/10.1186/s13756-018-0408-Z

[22] Offner, P.J., Moore, E.E. and Biffl, W.L. (1999) Male Gender Is a Risk Factor for Major Infections after Surgery. Archives of Surgery, 134, 935-940.

https://doi.org/10.1001/archsurg.134.9.935

[23] Langelotz, C., Mueller-Rau, C., Terziyski, S., Rau, B., Krannich, A., Gastmeier, P., et al. (2014) Gender-Specific Differences in Surgical Site Infections: An Analysis of 438,050 Surgical Procedures from the German National Nosocomial Infections Surveillance System. Visceral Medicine, 30, 114-117. https://doi.org/10.1159/000362100

[24] Al-Qurayshi, Z., Baker, S.M., Garstka, M., Ducoin, C., Killackey, M., Nichols, R.L., et al. (2018) Post-Operative Infections: Trends in Distribution, Risk Factors, and Clinical and Economic Burdens. Surgical Infections, 19, 717-722.

https://doi.org/10.1089/sur.2018.127

[25] Zhang, P., Lu, J., Jing, Y., Tang, S., Zhu, D. and Bi, Y. (2017) Global Epidemiology of Diabetic Foot Ulceration: A Systematic Review and Meta-Analysis. Annals of Medicine, 49, 106-116.

[26] Oladeinde, B.H., Omoregie, R., Olley, M., Anunibe, J.A. and Onifade, A.A. (2013) A 5 -Year Surveillance of Wound Infections at a Rural Tertiary Hospital in Nigeria. African Health Sciences, 13, 351-356. https://doi.org/10.4314/ahs.v13i2.22

[27] Kakoullis, L., Papachristodoulou, E., Chra, P. and Panos, G. (2021) Mechanisms of Antibiotic Resistance in Important Gram-Positive and Gram-Negative Pathogens and Novel Antibiotic Solutions. Antibiotics, 10, Article No. 415. https://doi.org/10.3390/antibiotics10040415

[28] Misha, G., Chelkeba, L. and Melaku, T. (2021) Bacterial Profile and Antimicrobial Susceptibility Patterns of Isolates among Patients Diagnosed with Surgical Site Infection at a Tertiary Teaching Hospital in Ethiopia: A Prospective Cohort Study. Annals of Clinical Microbiology and Antimicrobials, 20, Article No. 33. 
https://doi.org/10.1186/s12941-021-00440-Z

[29] McGuinness, W.A., Malachowa, N. and DeLeo, F.R. (2017) Vancomycin Resistance in Staphylococcus aureus. Yale Journal of Biology and Medicine, 90, 269-281.

[30] Tsige, Y., Tadesse, S., G/Eyesus, T., Tefera, M.M., Amsalu, A., Menberu, M.A., et al. (2020) Prevalence of Methicillin-Resistant Staphylococcus aureus and Associated Risk Factors among Patients with Wound Infection at Referral Hospital, Northeast Ethiopia. Journal of Pathogens, 2020, Article ID: 3168325.

https://doi.org/10.1155/2020/3168325

[31] Abbas, T.E., Adam, I., Elhassan, E.M., Eldin, I.E.M.T. and Rahman, M.A. (2017) Overuse of Prophylactic Antibiotics for Elective Caesarean Delivery in Medani Hospital, Sudan. F1000Research, 6, 1225. https://doi.org/10.12688/f1000research.11919.1

[32] Ahmed, A.M., Nasr, S., Ahmed, A.M. and Elkhidir, O. (2019) Knowledge, Attitude and Practice of Surgical Staff towards Preoperative Surgical Antibiotic Prophylaxis at an Academic Tertiary Hospital in Sudan. Patient Safety in Surgery, 13, Article No. 42. https://doi.org/10.1186/s13037-019-0224-2

[33] Hamid, M.H., Arbab, A.H. and Yousef, B.A. (2020) Bacteriological Profile and Antibiotic Susceptibility of Diabetic Foot Infections at Ribat University Hospital; a Retrospective Study from Sudan. Journal of Diabetes \& Metabolic Disorders, 19, 1397 1406. https://doi.org/10.1007/s40200-020-00660-8 